\title{
Evolution of miniaturization and the phylogenetic position of Paedocypris, comprising the world's smallest vertebrate Lukas Rüber*1, Maurice Kottelat ${ }^{2}$, Heok Hui Tan³, Peter KL ${ }^{3}{ }^{3}$ and Ralf Britz ${ }^{1}$
}

Address: ${ }^{1}$ Department of Zoology, The Natural History Museum, Cromwell Road, London SW7 5BD, UK, 2Route de la Baroche 12, Case postale 57, CH-2952 Cornol, Switzerland (permanent address) and Raffles Museum of Biodiversity Research, National University of Singapore, Kent Ridge, Singapore 119260 and ${ }^{3}$ Department of Biological Sciences, National University of Singapore, Kent Ridge, Singapore 119260

Email: Lukas Rüber* - l.ruber@nhm.ac.uk; Maurice Kottelat - mkottelat@dplanet.ch; Heok Hui Tan - dbsthh@nus.edu.sg; Peter KL Ng - dbsngkl@nus.edu.sg; Ralf Britz - r.britz@nhm.ac.uk

* Corresponding author

Published: 13 March 2007

BMC Evolutionary Biology 2007, 7:38 doi:10.1/86/147|-2/48-7-38
Received: 23 October 2006

Accepted: 13 March 2007

This article is available from: http://www.biomedcentral.com//47/-2/48/7/38

(C) 2007 Rüber et al; licensee BioMed Central Ltd.

This is an Open Access article distributed under the terms of the Creative Commons Attribution License (http://creativecommons.org/licenses/by/2.0), which permits unrestricted use, distribution, and reproduction in any medium, provided the original work is properly cited.

\begin{abstract}
Background: Paedocypris, a highly developmentally truncated fish from peat swamp forests in Southeast Asia, comprises the world's smallest vertebrate. Although clearly a cyprinid fish, a hypothesis about its phylogenetic position among the subfamilies of this largest teleost family, with over 2400 species, does not exist. Here we present a phylogenetic analyses of 227 cypriniform taxa, including 213 cyprinids, based upon complete mitochondrial DNA cytochrome $b$ nucleotide sequences in order to determine the phylogenetic position of Paedocypris and to study the evolution of miniaturization among cyprinids.

Results: Our analyses reveal a strongly supported sister group relationship (clade $C$ ) between Paedocypris and Sundadanio, another developmentally truncated miniature cyprinid. Clade $C$ was resolved as sister group of a larger clade characterized by small rasborine taxa (clade $D$ ). We found that miniaturised taxa are more numerous in the rasborine clade $A$, formed by clades $C$ and $D$, than in any other cyprinid clade. The consensus cytb in cyprinids includes 380 amino acids and an incomplete $\mathrm{T}$ - stop codon. We noted that a few cyprinids mostly rasborine taxa placed within clade $A$ had either a TAA or TAG stop codon, 376,378 , or $38 \mathrm{I}$ amino acids, and up to 10 base pairs (bp) of noncoding region before the 5 ' end of the tRNA-Thr. Our relaxed molecular clock estimates revealed high divergence times for the Sundadanio and Paedocypris clades and provide a first temporal framework for the evolution of miniaturization among cyprinids.

Conclusion: Paedocypris belongs to a clade (Rasborinae clade A) that shows recurrent miniaturization, including both taxa characterized by developmental truncation and by proportioned dwarfism. Its closest relative is another miniaturized taxon, the genus Sundadanio. We conclude that the miniaturized cyprinids with remarkable morphological novelties, like Paedocypris and Danionella, are at the same time the most developmentally truncated taxa. The miniaturized cyprinids with no or few developmental truncations like Boraras, Microrasbora, and Horadandia show no such evolutionary novelties.
\end{abstract}




\section{Background}

Miniaturisation, an evolutionary process that leads to dwarfed sexually mature organisms, is widespread among vertebrates and best documented in amphibians and fishes [1-4]. Miniaturized taxa are frequently characterized by a trend towards reduction and simplification of various structures and organs. In a number of cases such miniature taxa, in the example of fishes, species maturing at sizes under $20 \mathrm{~mm}$ [2], have defied various attempts over a number of decades to determine their phylogenetic position with any confidence. The two most prominent examples among bony fishes in this context are Schindleria, which had previously been assigned to various higher level taxa among teleosts and even been put in its own order, until it was shown to be a gobioid [5], and Sundasalanx, which was first described as a salmoniform [6], but later demonstrated to be a clupeoid [7].

We recently described a new genus of miniaturized cyprinids, Paedocypris, with two new species P. micromegethes and $P$. progenetica, both from Southeast Asia [8]. Although clearly a member of the Cyprinidae among the cypriniform Otophysi, the simplified anatomical structure of Paedocypris, combined with a number of highly derived autapomorphic characters, have made it difficult to develop a convincing hypothesis about its phylogenetic position among the subfamilies of this largest teleost family [9]. A phylogenetic framework, however, is essential to evaluate the number of evolutionary transitions from non-miniature to miniature among cyprinids, and thus, to determine whether Paedocypris is part of a larger group of miniaturized taxa or the consequence of an independent evolutionary event of miniaturization. Among cyprinids, 21 species from nine genera in South and Southeast Asia can be considered miniaturized [8,10-12]. Miniature cyprinids are absent from North America and Eurasia (not including India and southern Asia), however, 12 species in three genera are known from Africa [13]. To determine the phylogenetic position of Paedocypris among cyprinids, we performed a phylogenetic analysis based on DNA nucleotide sequence data from a large range of cypriniform representatives including many miniaturized taxa.

\section{Results \\ Cyprinid phylogenetics}

The phylogenetic analyses were based on an alignment of 1131 nucleotide sites excluding some positions at the $3^{\prime}$ end of the cyt $b$ gene. We were unable to amplify the $5^{\prime}$ end of the cyt $b$ for nine taxa despite designing several new primers located in the tRNA-Glu and internal reverse primers (Additional files 1 and 2). The cytochrome $b$ (cytb) in the analysed taxa consists of 376, 378, 380, or 381 amino acids, with 380 amino acid positions being the most common length of the ORF in cyprinids (Additional file 1). Most cyprinids show an incomplete T-- stop codon that is completed to a TAA stop codon posttranscriptionally by polyadenylation of the mRNAs [14]. We noted that a few cyprinids had either a TAA or TAG stop codon and up to 10 base pairs (bp) of noncoding region before the 5' end of the tRNA-Thr. Changes of the 3' end of the cytochrome $b$, the stop codon, noncoding region, and the beginning of the tRNA-Thr of the taxa used in this study are shown in Additional file 1. In this regard it is noteworthy to mention that both Paedocypris sp "Pulau Singkep" and "Banka" from Islands near Sumatra show a complete TAA stop codon, whereas $P$. sp "Kalimantan Tengah" and "Pontianak" from Borneo show an incomplete T-- stop codon [see Additional file 1].

The 50\% majority-rule consensus tree recovered from the partitioned Bayesian analysis of the complete cytochrome $b$ is depicted in Figure 1. As the focus of our study was to place Paedocypris within a larger phylogenetic framework, a detailed treatment of cyprinid intrarelationships based upon complete cytb is beyond our scope. We are aware that some nodes in Figure 1 are poorly supported or unresolved but this does not affect our conclusions. Clearly, more nucleotide sampling both from mitochondrial and nuclear DNA is needed to fully resolve the complex phylogenetic history of cyprinids.

Paedocypris was placed as sistergroup of Sundadanio with high support (1.0 posterior probability, clade $\mathrm{C}$ in Figure 1). The Paedocypris-Sundadanio clade $C$ was resolved with moderate support as sistergroup to clade D (Figure $1 ; 1.0$ posterior probability), which consists of an additional 21 rasborine taxa forming the Rasborinae clade A $(0.86$ posterior probability, clade A in Figure 1). Other taxa commonly classified as Rasborinae were not resolved in clade A, rendering the Rasborinae non-monophyletic (Figure 1 ). The Rasborinae clade $A$ was resolved as sister group of clade B (Figure 1; 0.99 posterior probability) consisting of the remaining cyprinid taxa with high support. The monophyly of the Cyprinidae received a posterior probability of 1.00 (Figure 1). ML gave identical results regarding the main cyprinid intrarelationships as BI (see Figure 2 ). The maximum observed pairwise genetic distance ( $\mathrm{p}$ distances) between Paedocypris individuals sampled from Sumatra and Borneo were $12.6 \%$, whereas the genetic distance between the two Sundadanio individuals (one from Borneo and the other with uncertain origin obtained through the aquarium trade, but presumably from Sumatra) was $13.5 \%$.

\section{Cyprinidae divergence time estimates}

The ML phylogram used for the PL analyses is depicted in Figure 2A. In both approaches, calibration based on substitution rate or fossil record, stem and crown group calibrations gave nearly identical results regarding cyprinid 


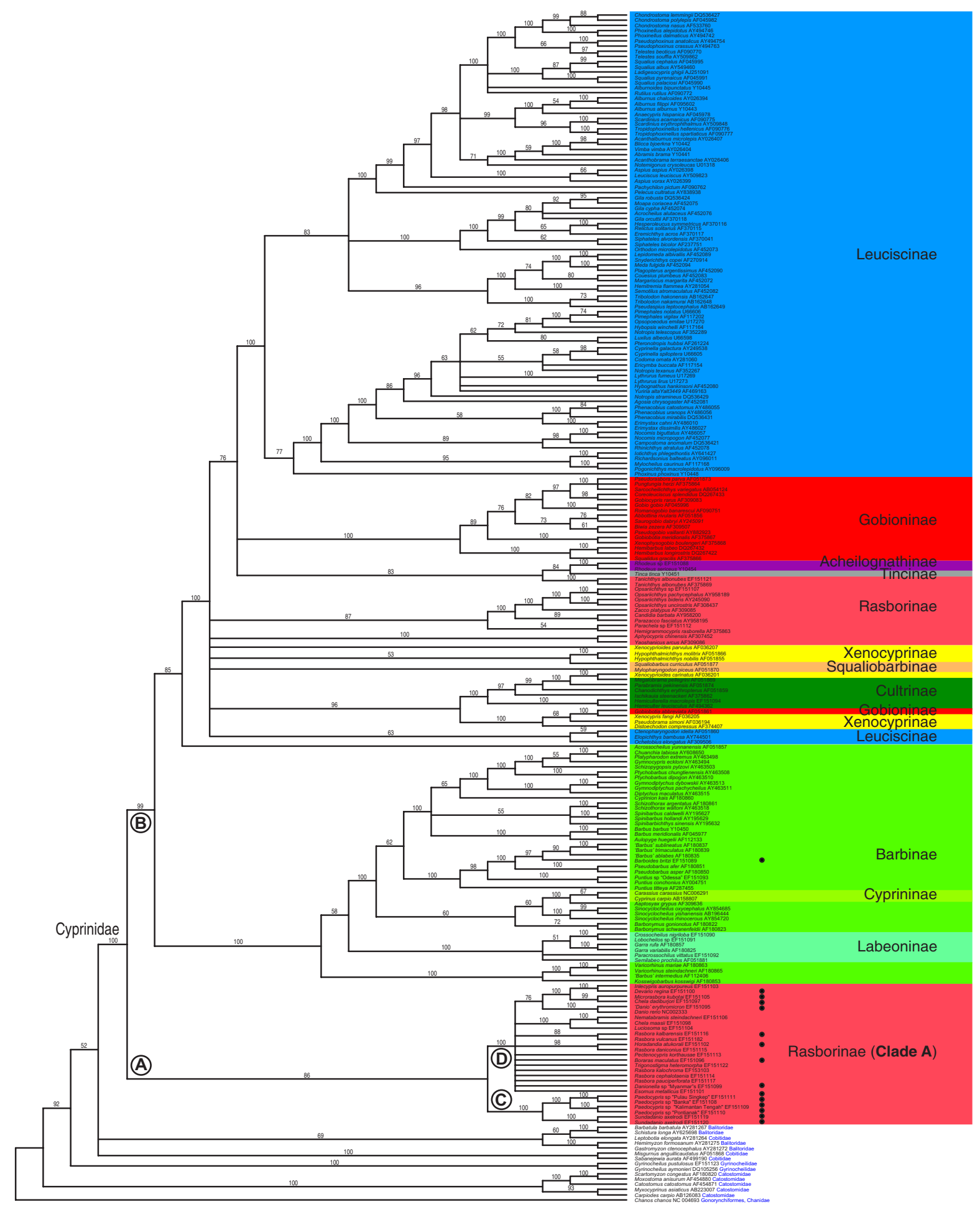

\section{Figure I}

Phylogeny of the Cyprinidae based upon the complete cytb nucleotide sequence data. This figure shows the 50\% majority rule consensus tree of 5000 MC3 sampled trees. Major clades discussed in the text are labelled A to D. Bayesian posterior probabilities (in percentage) are given above branches. Assignment of taxa to the eleven cyprinid subfamilies follows [24] with modifications by $[9,47]$ (subfamilies are illustrated with colour boxes, see Additional file I). A black filled circle next to the species name indicates miniature taxa. 

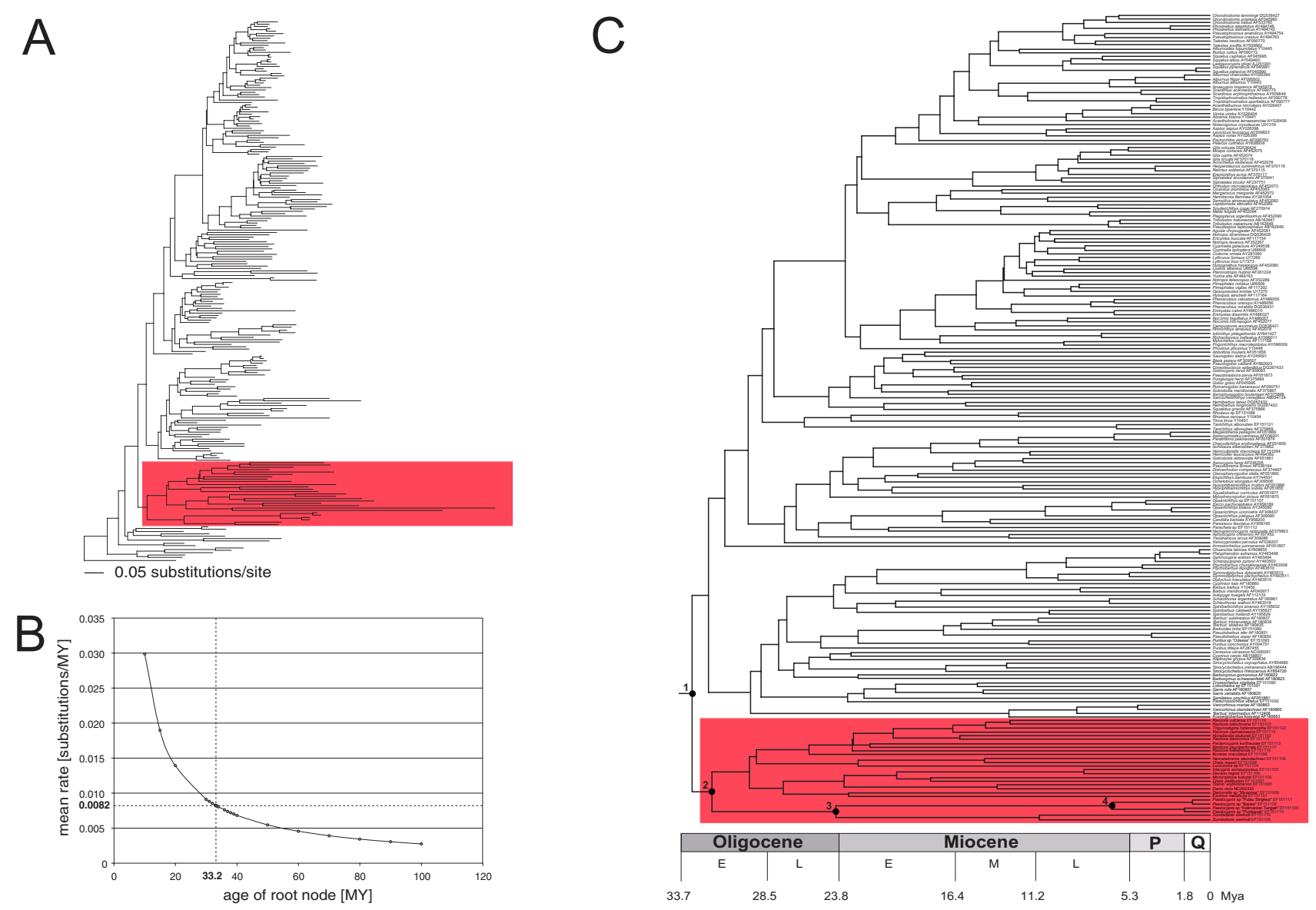

Figure 2

Relaxed molecular clock analysis of cyprinids based on complete cytb nucleotide sequence data. Relaxed molecular clock for cyprinids based on penalized likelihood (PL) and a calibration using a mean substitution rate of 0.0082 substitutions per site per million year (see text for details). A) ML phylogram based upon the complete cytb nucleotide sequence data. B) Relationship between root age and inferred mean substitution rate for the cyprinid tree. The tree was calibrated by iteration of the age of the root [44] until the mean rate equaled the cyprinid cytb clock [16] For each root age the optimal smoothing value for PL was assessed independently using the cross validation procedure implemented in r8s. A root age of $33.2 \mathrm{MY}$ resulted in a mean substitution rate of 0.0082 substitutions per site per million year [16]. C) Resulting chronogram using a fixed root age of 33.2 MY. The nodes labelled I-4 are mentioned in the text and in Table I. The Rasborinae clade A (see Figure I) is highlighted in both $A$ and $C$.

divergence time estimates (Table 1). We therefore focus on the results obtained using the crown group calibration. Applying the cyprinid cytb molecular clock of 0.0082 substitutions per site per million year resulted in a cyprinid crown group age of 33.2 MY (node 1 in Figure 2C), while the age of the MRCA of rasborins (Clade A) was $31.89 \mathrm{MY}$ (node 2 in Figure 2C), that of Paedocypris and Sundadanio was 23.97 MY (node 3 in Figure 2C), and that of Paedocypris was 6.34 MY (node 4 in Figure 2C) (Table 1). The inferred standard deviation (sd) of the substitution rate was 0.003 . In contrast, when the cyprinid tree was calibrated with fossil data constraining the crown group age to 51.9 MY (node 1 in Figure 2C), the MRCA of rasborines (Clade A) was found to be $49.86 \mathrm{MY}$ old (node 2 in Figure
2C), that of Paedocypris and Sundadanio 37.47 MY (node 3 in Figure 2C), and that of Paedocypris 9.91 MY (node 4 in Figure 2C), respectively (Table 1). The inferred mean substitution rate with this calibration was 0.0052 (sd 0.002) substitutions per site per million years.

\section{Evolution of miniaturization in rasborines}

The ML topology from the rasborine data set was used to perform character-state reconstruction for the evolution of miniaturization among Rasborinae clade A (Figure 1). Using both, unweighted parsimony and ML ancestral character state reconstruction we found that a miniature body size has evolved recurrently among rasborines from clade A (Figure 3). We note, however, that the topology of 
Table I: Molecular divergence time estimates of selected cyprinid nodes.

\begin{tabular}{|c|c|c|c|c|}
\hline \multirow[t]{2}{*}{ Taxa } & \multicolumn{2}{|c|}{ Substitution rate calibration } & \multicolumn{2}{|c|}{ Fossil calibration } \\
\hline & Crown group & Stem group & Crown group & Stem group \\
\hline MRCA Cyprinidae and its sister group & n.a & 34.20 & n.a & $51.90 \mathrm{a}$ \\
\hline MRCA Cyprinidae & 33.20 & 33.19 & 51.9 a & 50.38 \\
\hline MRCA Rasborinae (clade A)b & 31.89 & 31.89 & 49.86 & 48.42 \\
\hline MRCA Paedocypris and Sundadanio (clade C) & 23.97 & 23.99 & 37.47 & 36.41 \\
\hline MRCA Paedocypris & 6.34 & 6.36 & 9.91 & 9.67 \\
\hline Substitution rate & $0.0082^{c}$ & $0.0082^{c}$ & $0.0053^{d}$ & $0.0054^{d}$ \\
\hline Standard deviation (sd) & 0.0032 & 0.0032 & 0.0021 & 0.0021 \\
\hline Smoothing parameter for PL & 1.0 & 1.0 & 2.5 & 2.5 \\
\hline
\end{tabular}

This table lists inferred ages in million years for selected cyprinid nodes (nodes MRCA Cyprinidae, MRCA Rasborinae (clade A), MRCA Paedocypris and Sundadanio, and MRCA Paedocypris are labelled I-4 in Figure 2C), substitution rates, standard deviation and smoothing parameters used for the alternative calibration of a relaxed cyprinid molecular clock (substitution rate calibration and fossil calibration) with penalized likelihood (PL). The chronogram resulting from the substitution rate calibration (crown group) is shown in Figure $2 \mathrm{C}$.

$a=$ fixed root age; $b=$ Clades $A$ and $C$ refer to clade designations given in Figure I; $c=$ fixed substitution rate (see text for details); $d=$ inferred substitution rate.

clade D is not well resolved (Figure 1) and that additional mitochondrial and nuclear DNA sequence data as well as an increased taxon sampling is needed for a better understanding of the evolution of miniaturization in rasborine clade A.

\section{Discussion \\ Molecular phylogenetics}

To place Paedocypris within a larger phylogenetic framework we had to depend to a large degree on published cyt $b$ sequences, by far the most commonly used molecular phylogenetic marker for cyprinids thus far (e.g. [15-18]). While most of the cyprinid subfamilies are rather well represented in the GenBank/EMBL/DDBJ database, complete rasborine cytb sequences are scarce. This is surprising, since the Rasborinae is a particularly speciose and widespread subfamily. Only one representative of the rasborine clade A (Figure 1) could be obtained from GenBank (Danio rerio, NC 002333) whereas the other 26 species (clade A) were sequenced specifically for this study. We were unable to amplify the $5^{\prime}$ end of the cyt $b$ for nine of these taxa [see Additional file 1]. It is therefore possible that in some rasborines the tRNA-Glu is not located directly $5^{\prime}$ of the cyt $b$ or that it shows an unusual structure compared to the consensus teleost tRNA-Glu. This might partially explain the absence of published complete rasborine cyt $b$ nucleotide sequences.

\section{Divergence time estimates}

The results derived from the substitution rate calibration and those obtained under the fossil calibrations vary widely in the inferred cyprinid root ages (Table 1). While the root was fixed at an age of 51.9 My based on fossil evidence, using the substitution rate calibration we obtained a root age of 33.2 My (Table 1). A possible source of error in this calibration is the cyprinid cytb substitution rate used. Recently, it was shown that there is a problem of extrapolating molecular rates across different evolutionary timescales caused by marked differences between short-term and long-term substitution rates [19]. It is therefore likely that the cyprinid substitution rate we employed is inflated (faster short term substitution rates for the taxa used for the calculation [16] than the "real" long term cyprinid substitution rate) and hence, the divergence time estimates have been underestimated.

\section{Miniaturization}

The evolution of small size is a recurrent theme among teleosts and especially striking in cyprinid and gobioid fishes, which include the record holders for smallest vertebrates $[8,20,21]$. The recently described cyprinid genus Paedocypris contains the smallest fish and vertebrate species, $P$. progenetica, with females maturing at $7.9 \mathrm{~mm}$ standard length [8]. So far, the phylogenetic relationships of Paedocypris among the Cyprinidae are unclear due to its highly developmentally truncated anatomy. The mtDNA based phylogenetic analyses, reported herein are part of a dual approach to resolve this issue. An ongoing morphological study looks at non-truncated characters of Paedocypris and compares them with other cyprinid representatives (Britz and Conway in prep.). Our phylogenetic analyses of a large number of cyprinids consistently recovered Sundadanio as the sister group of Paedocypris. Sundadanio is a genus established for a single miniature 

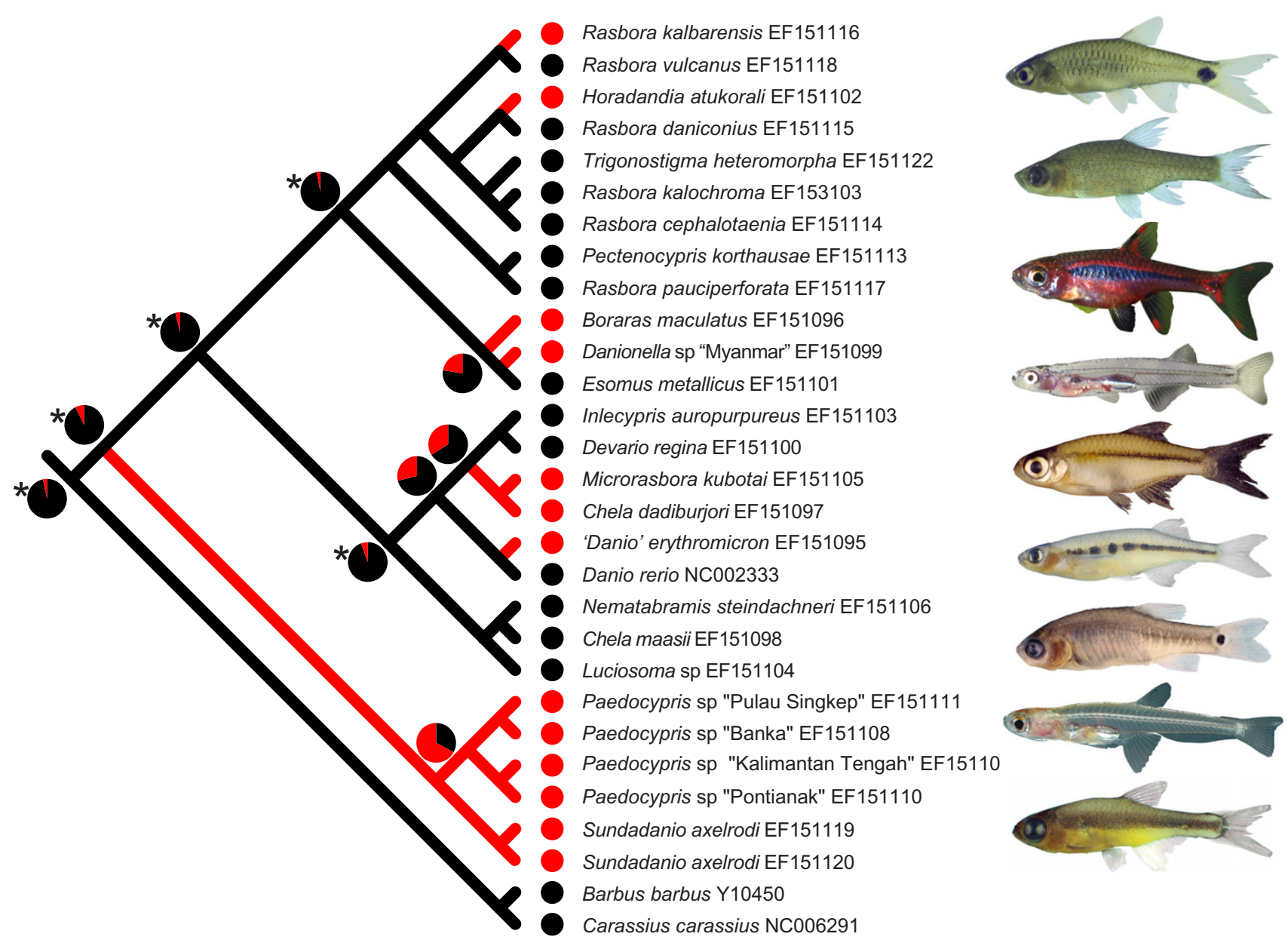

Figure 3

Evolution of miniaturization in the rasborine clade A. Tracing the evolution of miniaturization on the ML topology (one of three ML topologies; choice of topology does not alter conclusions) of the rasborine data set (clade A). The state 'miniature' is given in red colour, whereas the state 'non-miniature' is given in black. Results from both, unweighted parsimony and ML (selected nodes only), are shown. Significant ML reconstructions are indicated with an asterisk. Photographs of selected miniature rasborines mentioned in the text are given behind taxon names: Rasbora kalbarensis, Horadandia atukorali, Boraras brigittae, Danionella sp 'Myanmar', Microrasbora kubotai, Chela dadiburjori, 'Danio' erythromicron, Paedocypris progenetica, Sundadanio axelrodi.

species, $S$. axelrodi, originally described as a member of the genus Rasbora $[10,22]$. Sundadanio (which includes at least two or three undescribed species) has a maximum size of $22.5 \mathrm{~mm}$ SL [23] and occurs on Sumatra, Banka, Riau Archipelago, and different parts of Borneo.

Both Sundadanio and Paedocypris are part of a larger clade (Rasborinae clade A in Figure 1) comprising taxa that have been referred to in the systematic literature as Rasborinae [24] or Danioninae [25]. Among those, the genera Esomus, Luciosoma, Rasbora, Nematabramis, Chela, Inlecypris, Danio (= Devario), Brachydanio (= Danio), Bengala, Pseudorasbora, and possibly Thryssocypris, were considered by Howes [24] to form a monophyletic group, the Rasborini. The only more recent comprehensive phylogenetic study looking at relationships among some rasborine taxa is Fang [26], who focused on the so-called danionins. Regarding the position of Sundadanio, Fang ([26], p. 719) concluded: "The genus is obviously well characterized, and it is apparently a danionin taxon, but a precise phylogenetic placement is presently elusive." Based on our molecular results Sundadanio is the closest relative of Paedocypris.

Judging from the number of very small species, miniaturization seems to be much more frequent in the rasborine clade A cyprinids than in any other subfamily (Figure 1). In the taxa we have studied, miniaturization occurs in the Sundadanio/Paedocypris clade (clade C: Figure 1), in Danionella, 'Danio' erythromicron, Microrasbora, Horadandia, Boraras, Chela dadiburjori and in Rasbora kalbarensis. Based 
on our tree, we hypothesize that miniature taxa evolved at least seven times independently in rasborine clade A (Figure 3). The only other miniature cyprinid outside Rasborinae in our analysis is the African Barboides britzi, which groups with the other African Barbus-like cyprinids (Figure 1). Other miniature cyprinid taxa, which we were unable to include in the study, are Sawbwa resplendens, an Asian member of the Cyprininae, Tanichthys micagemmae, sometimes considered a rasborine, although its sister taxon $T$. albonubes was not resolved in the core rasborine clade A in our analyses (Figure 1), and nine African species of the genus 'Barbus' (Barbinae).

Our results indicate that Paedocypris is the sister genus of the miniaturized Sundadanio and part of a larger clade, the Rasborinae clade A (Figure 1). Paedocypris is thus not the result of an independent miniaturization event, but an extreme of the trend towards miniaturization in the Sundadanio - Paedocypris clade (Figure 3). Although miniature fishes, by definition, share the character 'maturing at sizes under $20 \mathrm{~mm}$ ' [2], the anatomical outcome of the process of miniaturization can be very different. Two extreme results are possible with various intermediate stages in between [27]: the miniaturized species may just be a dwarfed but otherwise identical image of its larger ancestor (Gould's proportioned dwarfism [28]), or it closely resembles an early developmental stage of the larger ancestor (commonly referred to as developmentally truncated species). Among the miniature cyprinids, an example for the first case is Boraras, which, except for a few reductions, closely resembles its larger relatives of the genus Rasbora [29]. Two clearly developmentally truncated miniature cyprinids are Danionella and Paedocypris that have the appearance and anatomical structure of larval cyprinids $[8,11]$.

Hanken [1] noted that miniaturization is often not only associated with the reduction of characters, but also with the evolution of morphological novelties and some of the developmentally truncated miniature cyprinids offer fascinating examples for this claim. Danionella is characterized by an anterior shift of the genital pore and anus in males so that both open between the enlarged pelvic fins [11], and by novel flanges, cartilages, and processes on the Weberian apparatus with unknown function. Males of the genus Paedocypris have a highly modified pelvic girdle, and pelvic fin rays and associated muscles that along with a conspicuous, keratinized knob of skin in front of the fins possibly function as a clasping organ, although its precise biological role is still unclear [8]. In contrast, species of the genus Boraras, the proportioned dwarfs, which are in roughly the same size class as Danionella and Paedocypris, reveal no such evolutionary novelties. Morphological novelties also seem to be lacking in some of the other miniaturized, but hardly developmentally truncated, cyprinids, like Horadandia, Sawbwa, Microrasbora, and 'Danio' erythromicron. With the establishment of Danio rerio, a member of rasborine clade $\mathrm{A}$, as a model organism for vertebrate developmental genetics [30] the proportioned dwarfs and the developmentally truncated miniatures offer a challenging system of "natural mutants" to study the loss of characters and the evolution of morphological novelties comparatively at a genetic level.

Kottelat et al. [8] pointed out that peat swamp forests in Southeast Asia house an unusually high number of miniature fishes. Regarding cyprinids only, this still holds true, as six out of the 12 miniature cyprinids occurring in Southeast Asia live in peat swamp forests and of these five exclusively so (i.e. are stenotopic). The continued study of these and other miniaturized fish is in jeopardy as their preferred habitats in Southeast Asia are being lost at an alarming rate [8].

\section{Conclusion}

Our phylogenetic analyses that include representatives of all major cyprinid lineages show a strongly supported sister group relationship between Sundadanio and Paedocypris, two developmentally truncated taxa. They were resolved as part of a larger clade containing small rasborines (rasborine clade A). Relaxed molecular clock analyses revealed unexpectedly old ages for the MRCAs of the Sundadanio - Paedocypris clade (clade C; Figure 1) and the Paedocypris and Sundadanio clades, respectively (Figure 1 and 3). Miniaturization seems to be a much more frequent event in the rasborine clade $\mathrm{A}$ than in any other cyprinid subfamily. Based on our phylogenetic hypothesis, miniature taxa evolved at least seven times independently in rasborine clade A including developmentally truncated taxa and taxa characterized by proportioned dwarfism. The rasborine clade $\mathrm{A}$ is not only an ideal group to study the evolution of miniaturization among vertebrates, but also to investigate the evolution of morphological novelties. While those miniature cyprinids that hardly show any developmental truncation generally lack morphological novelties, they are common in miniature, developmentally truncated cyprinids.

\section{Methods \\ Biological material, DNA isolation, and DNA sequencing}

To assess the molecular phylogenetic position of Paedocypris, DNA samples of 36 Cyprinidae, mostly Rasborinae, and one species of Gyrinocheilidae were specifically obtained for this study (appendix 1; see below). In addition, a total of 191 complete or nearly complete cytochrome $b$ (cyt $b$ ) sequences were obtained from GenBank (177 Cyprinidae, five Catostomidae, three Cobitidae, four Balitoridae, one species of Gyrinocheilidae, and one species of Gonorynchiformes as outgroup; see Additional file 1). Cytochrome $b$ has been the most important and most 
frequently used molecular marker in cyprinid phylogenetics, but we are aware that its phylogenetic performance might not be suitable to address cyprinid intrarelationships at all taxonomic levels [31]. However, we still chose to use cytb over alternative markers due to its huge taxonomic coverage that allowed wide ranging comparisons regarding the phylogenetic position of Paedocypris.

Whole fish or fin clips were preserved in $70-100 \%$ ethanol, and total genomic DNA was isolated from white muscle tissue or fin clips using the QIAGENE DNeasy Tissue kit. The complete cytochrome $b$ gene was amplified with two versatile primers DonGlu F and DonThr R [32]. For some taxa additional primers were used [see Additional file 2]. All PCR amplifications were conducted in $25 \mu \mathrm{l}$ reactions containing $75 \mathrm{mM}$ Tris- $\mathrm{HCl}(\mathrm{pH} 9.0), 2 \mathrm{mM}$ $\mathrm{MgCl} 2,0.4 \mathrm{mM}$ of each dNTP, $0.4 \mu \mathrm{M}$ of each primer, template DNA (10-100 ng), and Taq DNA polymerase (1 unit, Promega), using the following program on a $\mathrm{MJ}$ PTC-2000 thermal cycler: 1 cycle of $2 \mathrm{~min}$ at $94^{\circ} \mathrm{C}, 35$ cyles of 60 s at $94^{\circ} \mathrm{C}, 60$ s at $48-54^{\circ} \mathrm{C}$, and 90 s at $72^{\circ} \mathrm{C}$, and finally, 1 cycle of $5 \mathrm{~min}$ at $72^{\circ} \mathrm{C}$. PCR products were sequenced directly after PCR purification using the Millipore PCR cleanup kit.

Sequencing reactions were performed with the BigDye Terminator v1.1 Cycle Sequencing Kits (Applied Biosystems, Foster City, CA) following manufacturer's instructions in a $10 \mu \mathrm{l}$ volume with $1 \mathrm{pMol}$ of primer, $1 \mu \mathrm{l}$ of BigDye Terminator Mix, and 2-3 ng of DNA per 100 bps of PCR product. The cycling profile for the sequencing reaction consisted of 25 cycles of $10 \mathrm{~s}$ at $96^{\circ} \mathrm{C}, 5 \mathrm{~s}$ at $50^{\circ} \mathrm{C}$, and $4 \mathrm{~min}$ at $60^{\circ} \mathrm{C}$. Cycle sequencing products were purified using standard ethanol/sodium acetate precipitation and run on an Applied Biosystems $3730 \times 1$ DNA Analyzer. Sequences specifically obtained for this study have been deposited in GenBank [GenBank: EF151088$\underline{\text { EF151123 }}$ and EF153103 ].

\section{Sequence alignment and phylogenetic analyses}

The cytochrome $b$ nucleotide data set was aligned by eye. The alignment is available from TreeBASE. The phylogenetic analyses comprised the complete cyt $b$ of 228 taxa (including other families and outgroup; Appendix 1). The Akaike Information Criterion (AIC; [33]) implemented in MODELTEST v3.06 [34] was used to determine the evolutionary model that best fits the data set. The model selected was subsequently used for Bayesian inference (BI) and maximum likelihood (ML) analyses.

A Bayesian inference (BI) of cyprinid phylogeny was performed with MrBayes v3.1.2 [35] by Metropolis Coupled Markov Chain Monte Carlo (MC3) sampling for 2,000,000 generations (two independent runs each with four simultaneous $\mathrm{MC}$ chains; chain temperature 0.2 ; sample frequency 200; burnin 1,500,000 generations (see Results) under the GTR $+\mathrm{I}+\Gamma$ model as selected by MODELTEST v3.06. The cyt $b$ data set was run with three data partitions (1st, 2nd, and 3rd codon positions) and model parameters were estimated independently for each of the respective data partitions using the unlink command in MrBayes v3.1.2. Tracer v1.3 [36] was used to plot the - log likelihood scores against generation time to evaluate mixing, run convergence, and the burn-in needed before reaching stationarity. We then used PAUP* v4.0b10 [37] to reconstruct the $50 \%$ majority-rule consensus tree of the post burn-in trees. ML analyses were conducted with Garli v0.94 [38] under the GTR $+\mathrm{I}+\Gamma$ model and using the default settings.

\section{Evolution of miniaturization}

Ancestral character state reconstructions for the evolution of miniaturization in the rasborine clade A were performed based upon ML topology obtained with PAUP* from a restricted 29-taxon data set (henceforth referred to as the rasborine data set). Miniaturized taxa are defined as maturing at sizes under $20 \mathrm{~mm} \mathrm{[2].} \mathrm{Ancestral} \mathrm{character}$ state reconstruction was performed under unweighted parsimony and ML as implemented in Mesquite v1.06 $[39,40]$.

\section{Divergence times estimates}

Chronograms were constructed using penalized likelihood (PL, [41]), as implemented in r8s v1.70 [42] based on the ML phylogram to date major cladogenetic events. The TN algorithm and the additive penalty function was used for the PL analyses. In order to find the optimal smoothing parameter $(\lambda)$ for $P L$, cross-validation was performed over a range of values of $\lambda$ ranging from $10^{0}$ to $10^{2.8}$ in 15 steps.

To roughly estimate divergence times between clades of interest we used two approaches. The first approach does not rely on the fossil record, but instead assumes an average cyprinid cytb substitution rate of 0.0082 substitutions per site per million years. This substitution rate was derived for the same gene for European cyprinids based upon two independent, and well-dated geological events (formation of the strait of Korinthos and the opening of the Gibraltar strait after the Messinian salinity crisis) [16] and was recalculated by Rüber et al. [43]. An iterative approach was used to estimate divergence times for the cyprinid data set by adjusting the age of the cyprinid root (see below) until it fitted the average cyprinid substitution rate (see also [44]). The second approach makes use of the fossil record of cyprinids. The oldest known fossil of the Cyprinidae is Parabarbus sp. from the Early Eocene (Ypresian, 49.0 - 54.8 MYA; Obailinskaya formation in Kazakhstan; $[45,46])$. We used the median age of the Ypresian (51.9 MYA) to calibrate the cyprinid tree. Given the uncer- 
tainty of assigning Parabarbus sp. to either the stem or crown group Cyprinidae, we conducted both analyses using either the most recent common ancestor (MRCA) of cyprinids and its sister group or the MRCA of cyprinids as the fixed "cyprinid root", respectively.

\section{Abbreviations}

BI, Bayesian inference; bp, base pairs; cyt $b$, cytochrome $b$; MC3, Metropolis Coupled Monte-Carlo-Markov-Chains; $\mathrm{ML}$, maximum likelihood; MRCA, most recent common ancestor; MY, million years; MYA, million years ago; PL, penalized likelihood; sd, standard deviation.

\section{Authors' contributions}

All authors designed the study. MK and HHT were involved in sampling. LR carried out the molecular work and the analyses. All authors contributed to the preparation of the manuscript, $\mathrm{RB}$ is responsible for the parts dealing with miniaturization. They read and approved the final version.

\section{Additional material}

\section{Additional File 1}

Table 1 - Specimen information, GenBank accession numbers, and alignment of the 3' end of the cytb, stop codon, non coding region, and 5 ' end of tRNA-Thr of the taxa included in this study. This table lists the families, subfamilies, species, and GenBank accession numbers (including sequences directly obtained from GenBank; GenBank entries from this study are underlined) for the cytb nucleotide sequence data. Subfamily assignments of the cyprinid taxa follow [24] with modifications from $[9,47]$. The alignment of the 3' end of the cytb, stop codon, non coding region, and 5' end of tRNA-Thr is given to illustrate changes occurring in this nucleotide region (non coding region, and 5 ' end of tRNA-Thr are not shown for taxa with a complete mitochondrial genome entry in GenBank).

Click here for file

[http://www.biomedcentral.com/content/supplementary/14712148-7-38-S1.PDF]

\section{Additional File 2}

Table 2 - Additional primers used to amplify the complete cyt $\mathrm{b}$ of the taxa sequenced specifically for this study. This table lists the additional primers used for this study. For previously published primers the references are given, primers designed for this study are given $5^{\prime}$ to 3 '.

Click here for file

[http://www.biomedcentral.com/content/supplementary/14712148-7-38-S2.PDF]

\section{Acknowledgements}

We are grateful to Derrick Zwickl for his advise on Garli, Peter Foster for helping with running analyses on the Natural History Museum Beowulf cluster, Dieter Bork for providing the Danionella and Boraras photos, and Soraya Villalba and the three anonymous reviewers for valuable comments on the manuscript. We also would like to thank Julia Llewellyn-Hughes and Claire Griffin from the Natural History Museum DNA sequencing facility who provided expert technical assistance. Grant-in-Aid (ZR.A.S028000) from the Department of Zoology, Natural History Museum of London to LR has funded this project.

\section{References}

I. Hanken J: Adaptation of bone growth to miniaturization of body size. In Bone, Bone Growth Volume 7. Edited by: Hall BK. Boca Raton, Fla: CRC Press; 1993:79-104.

2. Weitzman SH, Vari RP: Miniaturization in South American freshwater fishes; an overview and discussion. Proceedings of the Biological Society of Washington 1988, I 0 I:444-465.

3. Miller PJ: Adaptivness and implications of small size teleosts. Symposium of the Zoological Society London 1979, 4:263-306.

4. Hanken J, Wake DB: Miniaturization of body size: organismal consequences and evolutionary significance. Annual Review of Ecology and Systematics 1993, 24:501-519.

5. Johnson GD, Brothers EB: Schindleria: a paedomorphic goby (Teleostei: Gobioidei). Bulletin of Marine Science 1993, 52:44I-47I.

6. Roberts TR: Sundasalangidae a new family of minute fresh water salmoniform fishes from Southeast Asia. Proceedings of the California Academy of Sciences 1981, 42:295-302.

7. Siebert DJ: Notes on the anatomy and relationships of Sundasalanx Roberts (Teleostei, Clupeidae), with descriptions of four new species from Borneo. Bulletin of the Natural History Museum London (Zoology) 1997, 63:13-26.

8. Kottelat M, Britz R, Tan HH, Witte KE: Paedocypris, a new genus of Southeast Asian cyprinid fish with a remarkable sexual dimorphism, comprises the world's smallest vertebrate. Proceedings of the Royal Society B-Biological Sciences 2006, 273:895-899.

9. Nelson G]: Fishes of the World. 4th edition. New York: John Wiley \& Sons; 2006.

10. Kottelat M, Vidthayanon C: Boraras micros, a new genus and species of minute freshwater fish from Thailand (Teleostei: Cyprinidae). Ichthyological Exploration of Freshwaters 1993, 4: $|6|-\mid 76$.

II. Britz R: Danionella mirifica, a new species of miniature fish from Upper Myanmar (Ostariophysi: Cyprinidae). Ichthyological Exploration of Freshwaters 2003, 14:217-222.

12. Freyhof J, Herder F: Tanichthys micagemmae, a new miniature cyprinid fish from central Vietnam (Cypriniformes: Cyprinidae). Ichthyological Exploration of Freshwaters 2001, I 2:21 5-220.

13. Conway KW, Moritz T: Barboides britzi, a new species of miniature cyprinid from Benin (Ostariophysi: Cyprinidae), with a neotype designation for $B$. gracilis. Ichthyological Exploration of Freshwaters 2006, I 7:73-84.

14. Ojala D, Montoya J, Attardi G: tRNA punctuation model of RNA processing in human mitochondria. Nature I98I, 290:470-474.

15. Briolay J, Galtier N, Brito RM, Bouvet Y: Molecular phylogeny of Cyprinidae inferred from cytochrome $b$ DNA sequences. Molecular Phylogenetics and Evolution 1998, 9:100-108.

16. Zardoya R, Doadrio I: Molecular evidence on the evolutionary and biogeographical patterns of European cyprinids. Journal of Molecular Evolution 1999, 49:227-237.

17. Cunha C, Mesquita N, Dowling TE, Gilles A, Coelho MM: Phylogenetic relationships of Eurasian and American cyprinids using cytochrome b sequences. Journal of Fish Biology 2002, 6 I:929-944.

18. Xiao WH, Zhang YP, Liu HZ: Molecular systematics of Xenocyprinae (Teleostei: Cyprinidae): Taxonomy, biogeography, and coevolution of a special group restricted in East Asia. Molecular Phylogenetics and Evolution 2001, 18:163-173.

19. Ho SYW, Phillips MJ, Cooper A, Drummond AJ: Time dependency of molecular rate estimates and systematic overestimation of recent divergence times. Molecular Biology and Evolution 2005, 22: $|56|-1568$.

20. Winterbottom R, Emery AR: Trimmatom nanus new genus new species and Trimmatom offucius new species of gobiid fishes (Perciformes) from the Chagos Archipelago, Central Indian Ocean. Environmental Biology of Fishes 1981, 6:139-150.

21. Watson W, Walker HJ Jr: The world's smallest vertebrate, Schindleria brevipinguis, a new paedomorphic species in the family Schindleriidae (Perciformes: Gobioidei). Records of the Australian Museum 2004, 56:139-142.

22. Brittan MR: Rasbora axelrodi, a new cyprinid from Indonesia. Tropical Fish Hobbyist 1976, 25:92, 94-96, 98. 
23. Kottelat M, Witte KE: Two new species of Microrasbora from Thailand and Myanmar, with two new generic names for small Southeast Asian cyprinid fishes (Teleostei: Cyprinidae). Journal of South Asian Natural History 1999, 4:49-56.

24. Howes G: Systematics and biogeography. In Cyprinid Fishes- Systematics, biology and exploitation. Fish and Fisheries Series 3 Edited by: Winfield IJ, Nelson JS. London: Chapman \& Hall; |99|:|-33.

25. Weber M, de Beaufort LF: The fishes of the Indo-Australian Archipelago. In Ostariophysi: II Cyprinoidea, Apodes, Synbranchi Volume 3. Leiden: EJ Brill; 1916.

26. Fang F: Phylogenetic analysis of the Asian cyprinid genus Danio (Teleostei, Cyprinidae). Copeia 2003, 2003:7|4-728.

27. Britz R, Kottelat M: Descriptive osteology of the family Chaudhuriidae (Teleostei, Synbranchiformes, Mastacembeloidei), with a discussion of its relationships. American Museum Novitates 2003, 34 | 8: I-62.

28. Gould SJ: Geometric similarity in allometric growth: a contribution to the problem of scaling in the evolution of size. The American Naturalist 1971, 105: II3.

29. Conway KW: Monophyly of the genus Boraras (Teleostei: Cyprinidae). Ichthyological Exploration of Freshwaters 2005, I 6:249-264.

30. Meyer A, Biermann CH, Ortí G: The phylogenetic position of the zebrafish (Danio rerio), a model system in developmental biology: an invitation to the comparative method. Proceedings of the Royal Society of London Series B 1993, 252:23 I-236.

31. Miya M, Saitoh K, Wood R, Nishida M, Mayden RL: New primers for amplifying and sequencing the mitochondrial ND4/ND5 gene region of the Cypriniformes (Actinopterygii: Ostariophysi). Ichthyological Research 2006, 53:75-8I.

32. Rüber L, Britz R, Tan HH, Ng PKL, Zardoya R: Evolution of mouthbrooding and life-history correlates in the fighting fish genus Betta. Evolution 2004, 58:799-8I3.

33. Akaike $\mathrm{H}$ : Information theory and the extension of the maximum likelihood principle. Proceedings of the Second International Symposium on Information Theory 1973.

34. Posada D, Crandall K: Modeltest: testing the model of DNA substitution. Bioinformatics 1998, I4:817-818.

35. Huelsenbeck JP, Ronquist FR: MrBayes: Bayesian inference of phylogeny. Bioinformatics 200I, I 7:754-755.

36. Rambaut A, Drummond AJ: Tracer vI.3. [http:// evolve.zoo.ox.ac.uk].

37. Swofford DL: PAUP*: phylogenetic analysis using parsimony (*and other methods), version 4.0b I 0. Sunderland, US: Sinauer Associates; 2002.

38. Zwickl DJ: Garli - Genetic Algorithm for Rapid Likelihood Inference. [http://www.bio.utexas.edu/faculty/antisense/garli/ Garli.html].

39. Maddison WP, Maddison DR: Mesquite: A modular system for evolutionary analysis. Version I.I2 [http://mesquiteproject.org].

40. Maddison WP, Maddison DR: StochChar: A package of Mesquite modules for stochastic models of character evolution. Version I.I [http://mesquiteproject.org].

4I. Sanderson MJ: Estimating absolute rates of molecular evolution and divergence times: A penalized likelihood approach. Molecular Biology and Evolution 2002, 19:101-109.

42. Sanderson MJ: r8s: inferring absolute rates of molecular evolution and divergence times in the absence of a molecular clock. Bioinformatics 2003, 19:301-302.

43. Rüber L, Britz R, Kullander SO, Zardoya R: Evolutionary and biogeographic patterns of the Badidae (Teleostei: Perciformes) inferred from mitochondrial and nuclear DNA sequence data. Molecular Phylogenetics and Evolution 2004, 32:1010-1022.

44. Leys R, Watts CHS, Cooper SJB, Humphreys WF: Evolution of subterranean diving beetles (Coleoptera: Dytiscidae: Hydroporini, Bidessini) in the arid zone of Australia. Evolution 2003, 57:2819-2834.

45. Patterson C: Osteichthyes: Teleostei. In The Fossil Record 2 Edited by: Benton MJ. London: Chapman \& Hall; 1993:62I-656.

46. Sytchevskaya EK: Palaeogene freshwater fish fauna of the USSR and Mongolia. Trudy Sovmestnaya Sovetsko-Mongol'skaya Paleontologicheskaya Ekspeditsiya 1986, 29:I-I57. [in Russian, with English summary]

47. Arai R, Kato K: Gross morphology and evolution of the lateral line system and infraorbital bones in bitterlings (Cyprinidae, Acheilognathinae), with an overview of the lateral line sys- tem in the family Cyprinidae. University Museum, University of Tokyo, Bulletin 2003, 40: I-42.
Publish with Bio Med Central and every scientist can read your work free of charge

"BioMed Central will be the most significant development for disseminating the results of biomedical research in our lifetime. "

Sir Paul Nurse, Cancer Research UK

Your research papers will be:

- available free of charge to the entire biomedical community

- peer reviewed and published immediately upon acceptance

- cited in PubMed and archived on PubMed Central

- yours - you keep the copyright 